\title{
MERCADOLOGIA E TURISMO: ANÁLISE DA EFETIVIDADE DO COMPOSTO DE PRODUTO DE EMPRESAS DE ALIMENTOS E BEBIDAS DO ESTADO DE SÃO PAULO
}

\author{
Fábio Luciano Violin, Leonardo Giovane Moreira Gonçalves \\ Universidade Estadual Paulista - UNESP, curso de Turismo, Campus Experimental de Rosana, SP. E-mail: \\ violin@rosana.unesp.br
}

\begin{abstract}
RESUMO
A competição entre organizações e setores tem se acirrado ano a ano e tal entendimento tem sido estudado por centenas senão milhares de pesquisadores em todo mundo. Nesse sentido o objetivo deste estudo foi o de analisar ao longo do período de 2014 até 2017 os planos de ação ou elementos equivalentes como planos setoriais de marketing a efetividade das empresas em categorias vinculadas ao setor de alimentos e bebidas. A metodologia contou com a definição do objeto de análise os planos de ação com apontamentos de frequência de itens que apareceram ao longo dos anos nominados em tais planos especificamente no composto de produto. Os resultados apontam para elevado grau de efetividade com especial atenção ao fato de que organizações convencionais têm disputado mercado com organizações de grande porte distintivamente. Os resultados apontam para ganhos de efetividade e conclui-se que o composto tem sido trabalho de modo efetivo.

Palavras-chave: Marketing, Composto de Marketing, Estratégia, Turismo, Alimentos e Bebidas.

\section{MERCADOLOGY AND TOURISM: ANALYSIS OF THE EFFECTIVENESS OF THE COMPOUND OF THE COMPANY OF FOOD AND BEVERAGES OF THE STATE OF SÃO PAULO}

\begin{abstract}
The competition between organizations and sectors has been fierce year by year and such an understanding has been studied by hundreds if not thousands of researchers around the world. In this sense, the objective of this study was to analyze, during the period from 2014 to 2017, action plans or equivalent elements as sectoral marketing plans, the effectiveness of companies in categories linked to the food and beverage sector. The methodology relied on the definition of the object of analysis the action plans with frequency notes of items that appeared over the years nominated in such plans specifically in the product compound. The results point to a high degree of effectiveness with special attention to the fact that conventional organizations have been disputing market with large organizations distinctively. The results point to gains in effectiveness and it is concluded that the compound has been working effectively.
\end{abstract}

Keywords: Marketing, Marketing Mix, Strategy, Tourism, Food and Beverages.

\section{INTRODUÇÃO}

De forma geral, a demanda por determinados pelo desejo por produtos específicos, aliado à disposição e capacidade de adquiri-los. O poder de compra do indivíduo transforma o desejo em demanda (KOTLER, 2009). Em relação à alimentação, a compra pode ser resultante da necessidade fisiológica de se alimentar ou da necessidade de obtenção de prazer a partir do consumo de determinado alimento.

Assim, a aquisição de um produto constitui a tentativa de se satisfazer um desejo específico. A busca de satisfação das necessidades e desejos do público-alvo é o que garante a lucratividade das empresas (KOTLER, 2009). 
Os restaurantes e bares fazem parte do cotidiano da população e, consequentemente, do turista durante sua viagem. Por essa conotação - de elemento do cotidiano - esses estabelecimentos costumam ser utilizados como forma distintiva de se oferta produtos e serviços.

Há alguns anos se insere a ideia de busca pela vantagem competitiva, que é definida por Porter (1989) como as ações ofensivas ou defensivas para criar uma posição numa indústria, para enfrentar com sucesso as forças competitivas e assim obter retorno maior sobre o investimento.

Hax e Majluf (1996) ampliam a concepção ao apregoarem que estratégia é o conjunto de decisões coerentes, unificadoras e integradoras que determina e revela a vontade da organização em termos de objetivos de longo prazo, programa de ações e prioridade na alocação de recursos.

Boone e Kurtz (2015) destacam que o Composto de Marketing, por meio de seus elementos, constituinte podem permitir através da correta execução de ações que surja a chamada vantagem competitiva através da combinação de três etapas de interação: a Consistência, Integração e Alavancagem.

Considerando então a mutabilidade da tecnologia, da concorrência e dos próprios consumidores, aponta-se a emergência do Marketing, que deriva da mercadologia, que é entendida como o estudo das relações entre organizações e seus consumidores, especialmente, atrelada as suas variáveis controláveis determinadas por McCarthy em 1960.

McCarthy (1997) foi o pesquisador propulsor do conceito e discussão do contexto de explicação das variáveis controláveis de Marketing popularizadas especialmente nos países de origem capitalista e as categorizou em quatro partes: Produto, Preço, Promoção (Comunicação) e Praça (Logística).

Tais variáveis são chamadas de Mix Marketing ou Composto de Marketing no Brasil. Tais variáveis representam itens que compõem o conjunto de ações pelas quais organizações de todos os setores e portes podem adaptar os itens pertencentes ao composto de Marketing para desenvolverem suas ações junto ao mercado.

As ações de Marketing visam em essência proporcionar satisfação na relação entre uma organização e seus clientes. O conceito contemporâneo de marketing engloba a construção de um satisfatório relacionamento em longo prazo, no qual os indivíduos ou grupos de compradores potenciais obtém aquilo que desejam ou necessitam e estão habilitados a comprá-los. Diante disso, a gestão efetiva das estratégias mercadológicas relacionadas ao composto de marketing pode ser um elemento efetivo na manutenção da competitividade das empresas do setor de alimentos e bebidas.

McCarthy (1997) classificou quatro tipos de ferramentas, os quais denominou os quatro Ps do marketing: produto, preço, ponto de venda e promoção. Esses fatores são inter-relacionados e decisões em uma área afetam a outra.

Considerando a variável produto são analisados aspectos como formulação, características, produção, qualidade, marca, design entre outros. O mesmo pode ser composto de partes tangíveis e intangíveis.

Kotler (2012, p. 33) define produto como "algo que pode ser oferecido para satisfazer uma necessidade ou desejo". O marketing influencia os consumidores em relação aos seus desejos, o que inclui a escolha do destino de sua viagem.

Nesses termos, indica-se que o objetivo do presente estudo estabeleceu-se na análise comparativa dos planos de ação - especificamente de empresas do setor de Alimentos e Bebidas com foco no composto de produto, em empresas do estado de São Paulo no período de 2014 a 2017.

Os gestores devem elaborar estratégias de marketing que se adaptem à posição e aos recursos da empresa por isso, a análise constante e infinita do mercado, a atualização dos segmentos mais atrativos, a avaliação das forças e fraquezas da empresa e dos concorrentes e, consequentemente, a definição de planos de marketing anuais com planos de ação totalmente 
direcionados para atender às necessidades dos clientes é de vital importância para a manutenção saudável da empresa nos seus mercados de atuação.

Observa-se que a estruturação das estratégias mercadológicas evidenciadas nos dados levantados apontam para maior refinamento das ações mercadológicas, tal apontamento encontra seu fiel depositário nas interligações observáveis ao longo do conjunto de elementos pertinentes ao composto mercadológico e o nível correspondente de refinamento.

O senso comum talvez apontasse para uma possível superioridade das organizações de maior porte ou das que integram o ramo de fast food em detrimento de organizações menores ou mesmo de estrutura familiar. Tal lógica, ao menos para o grupo pesquisado, não se mostrou verdadeira.

\section{METODOLOGIA}

Para a montagem da base teórica do estudo foram utilizadas fontes secundárias como livros e artigos de natureza científica.

O público alvo foram organizações que tem no setor de Alimentos e Bebidas sua estrutura de oferta mercadológica. Partindo dessa prerrogativa, categorizou-se quatro tipos de empresas: as que atuam em shopping center, as que atuam juntas aos meios de hospedagem (especificamente, restaurantes de hotéis); as que se encontram em unidades conjugadas a postos de combustíveis ou de parada e as que se encontram como oferta isolada em rodovias ou estradas de acesso e por fim, as convencionais, ou seja, aquelas que se encontram nas ruas e avenidas das cidades.

A amostra manteve-se no estado de São Paulo e atingiu vinte e três cidades (ordem alfabética): Americana; Araraquara; Assis; Bauru; Botucatu; Campinas; Franca; Guaratinguetá; Jaú; Jundiaí; Marília; Mogi das Cruzes; Ourinhos; Piracicaba; Presidente Prudente; Rio claro; Rosana; São Bernardo do Campo; São Carlos; São José do Rio Preto; São Paulo; São Pedro e Sorocaba.

O objeto de interesse e atuação foram os planos de ação ou documentos equivalentes que demonstrassem a forma de atuação mercadológica das organizações ao longo do período de 2014 até 2017. A participação foi condicionada aos seguintes requisitos: ter um plano de ação ou documento que indicasse a forma de atuação da organização ao longo do período de interesse (2014 -2017) no aspecto mercadológico; que se enquadrasse em uma das categorias destacadas no próximo parágrafo e que disponibilizasse tal material de modo irrestrito para a aferição da efetividade das ações de cada elemento do composto de Marketing em cada uma das vertentes do setor de Alimentos e Bebidas contempladas no estudo.

Após 347 contatos, foi possível obter dados de 36 organizações que atuam em shopping center, 29 restaurantes de hotéis, 22 empresas que encontram em rodovias e estradas de acesso e 28 restaurantes nominados como convencionais. Desse modo, a amostra fica caracterizada como por conveniência configurando acessoriamente sua natureza qualitativa, apesar da apresentação de dados estatísticos.

O levantamento e análise se deu a partir dos itens marca, qualidade, estilo, design, garantias, variedade da oferta e características do produto expressa no texto com a observação da frequência e tipo de discurso recorrente expressos ao longo do período nos planos de ação ou documentos equivalentes.

\section{RESULTADOS}

Considerando as pretensões do estudo aponta-se que buscou-se através da análise dos dados advindos das organizações compreender e expressar valores que fossem próximos das ações das organizações em cada um dos elementos do composto de Marketing. Dentro de cada composto, buscou-se aferir as médias de proficiência para cada item. 
Nem sempre foi possível categorizar de modo irrestrito o elemento pois, a adaptação da ferramenta mercadológica é algo latente e precisa considerar as particularidades do setor de Alimentos e Bebidas.

Buscou-se levantar a média de proficiência das organizações baseando a análise nas entrevistas prestadas e no questionário respondido.

Figura 1: Efetividade do Composto de Produto

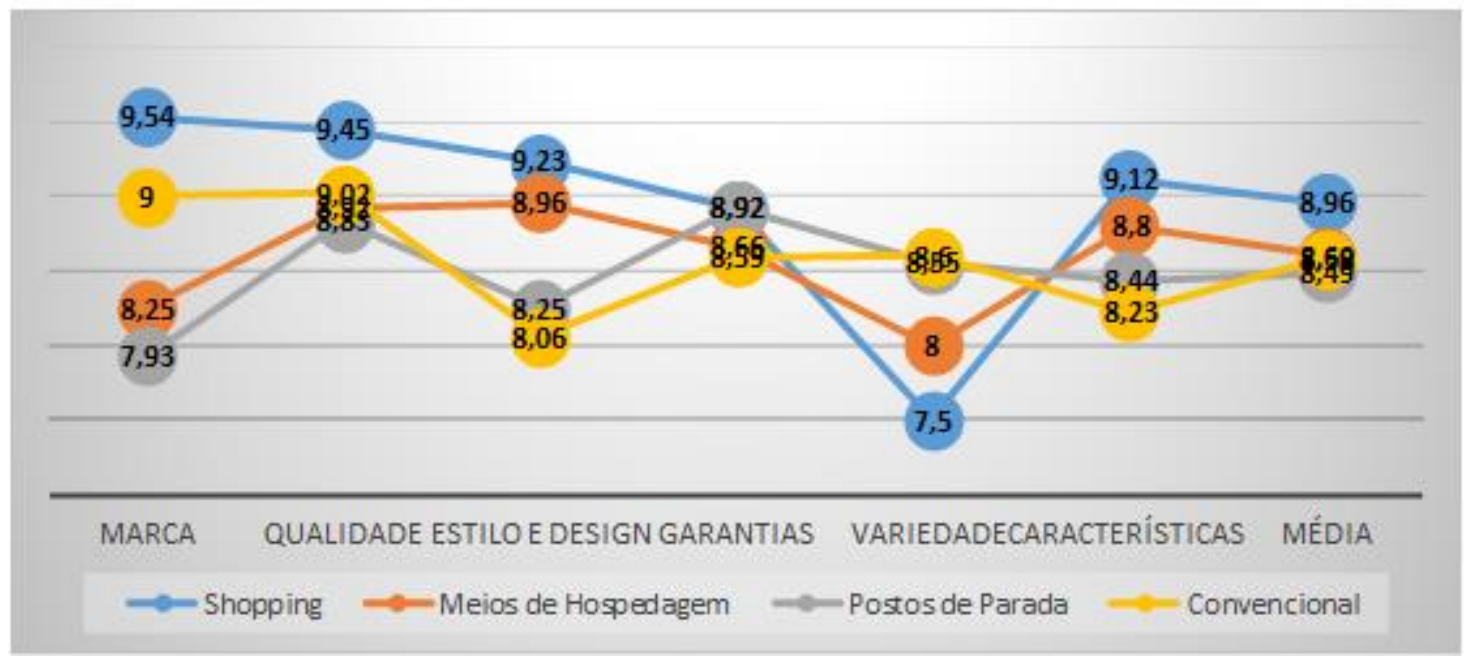

Aponta-se que, a marca é elemento, segundo 97\% das empresas, vital para a continuidade e que todos os elementos que compõem a oferta, quando "somados" refletem o posicionamento na mente do consumidor de uma marca de boa ou má qualidade.

\section{DISCUSSÃO}

Observa-se refinamento no trato da oferta das organizações, de modo médio. Elementos como marca, qualidade, estilo e design além do trabalho com as características do que é oferta apresentam elevada menção de refinamento dentro da amostra.

O elemento garantia bastante utilizado com produtos físicos, aqui se entende não somente como tal, mas para além, os dados apontaram para as garantias como indicadores advindos dos processos de elaboração e experiência de consumo dos clientes.

O elemento variedade, nesse estudo, traz uma particularidade. Entendeu-se como variedade o conjunto dos itens ofertados, porém, observa-se que os empreendimentos que apresentam maior refinamento são os que mantêm maior padronização.

Não necessariamente esse item é valorizado pelo consumidor, contudo, a padronização ao mesmo tempo traz como benefício e gargalo o mesmo sabor, apresentação e estrutura do que é ofertado ao longo do tempo.

\section{CONCLUSÃO}

Observa-se que o composto de produto tem sido um dos itens que apresenta maior refinamento por parte das organizações. Estudos advindos de pesquisadores como Kotler (2009) e Seth et al. (2013) apontam para expressa busca por refinamento em relação ao item que caracteriza a oferta de produtos e serviços aos consumidores.

Considerando a amostra aferida observa-se que ao longo dos anos os planos apresentaram clara evolução especialmente no refinamento da oferta dos produtos e serviços.

O equacionamento mais dificilmente observado pelo consumidor insere-se no item garantia, o qual as organizações de modo geral, consideram ao estabelecerem ações em termos 
de segurança alimentar, limpeza do ambiente, cuidado com asseio e estrutura de oferta dos itens aos consumidores.

A questão que trata da marca está claramente enunciada em todos os planos de ação. Pride et al. (2006) e Perreault e McCarthy (2005) destacam a importância desse item na consideração dos consumidores quando forem readquirir produtos e serviços similares. No contexto do estudo a marca figurou como item primordial de ação destacada ao longo dos anos em praticamente todos os planos de ação;

Aproximadamente $40 \%$ das organizações possuem valores e pessoas/setores específicos para gerenciarem o relacionamento com a marca.

Conclui-se que dentro da amostra pesquisada as organizações estabelecidas em shopping center tem na média a maior proficiência na gestão desse elemento do composto, porém, as empresas nominadas como convencionais, as de postos de parada e as localizadas em meios de hospedagem apresentam centros de efetividade especialmente quanto a definição das características da oferta além da qualidade e a forma de tentarem designar garantias.

Curiosamente as empresas localizadas em shoppings centers geralmente pertencem a cadeias de alimentação e apresentam na variedade sua menor indicação de frequência e efetividade.

\section{REFERÊNCIAS bibliográficas}

BOONE, L. E.; KURTZ, D. L. Contemporary Marketing, 16th Edition. London: Cengage Learning. 2015.

ENGEL, J. F.; BLACKWELL, R. D.; MINIARD, P.W. Consumer Behavior. 10th. Ed. Chicago: Dryden Press, 2000.

HAX, Arnold C. \& MAJLUF, Nicolas S. The Strategy Concept and Process. Englewood Cliffs, NJ: Prentice-Hall, 1996.

KOTLER, P. Administração de marketing. 14. Ed. São Paulo, Person, 2012.

KOTLER, P. Marketing para o século XXI: como criar, conquistar e dominar mercados. São Paulo: Ediouro, 2009.

MCCARTHY, G. Marketing essencial: uma abordagem gerencial e global. São Paulo: Atlas, 1997.

PERREAULT, W. D.; McCARTHY, E. J. Basic Marketing A Global Managerial Approach, 15th ed. Boston: McGraw-Hill, 2005.

PORTER, Michael E. Vantagem Competitiva. Rio de Janeiro, Campus. 1989.

PRIDE, W.M.; FERRELL, O.C. Marketing: Concepts and Strategies, 13th ed. Boston: Houghton Mifflin, 2006.

SHETH, J.N.; SISODIA, R.S.; SHARMA, A. The Challenges of Improving Marketing Productivity and Performance. Journal of Marketing Theory. 2013. Disponível em <http://www.jagsheth.com/marketing-theory/the-challenges-of-improving-marketingproductivity-and-performance/>. Acesso em 27 de Março de 2017. 